\title{
Towards maximized utilization of iridium for the acidic oxygen evolution reaction
}

\author{
Marc Ledendecker ${ }^{1, \S}(\bowtie)$, Simon Geiger ${ }^{1, \S}$, Katharina Hengge ${ }^{1}$, Joohyun Lim ${ }^{1}$, Serhiy Cherevko ${ }^{3}$, Andrea M. Mingers ${ }^{1}$, \\ Daniel Göhl ${ }^{1}$, Guilherme V. Fortunato ${ }^{1,5}$, Daniel Jalalpoor ${ }^{2}$, Ferdi Schüth ${ }^{2}$, Christina Scheu ${ }^{1}$, and Karl J. J. Mayrhofer $\left.{ }^{1,3,4}(\bowtie)\right)$ \\ ${ }^{1}$ Department of Interface Chemistry and Surface Engineering, Nanoanalytics and Interfaces Max-Planck-Institut für Eisenforschung GmbH, 40237 \\ Düsseldorf, Germany \\ ${ }^{2}$ Department of Heterogeneous Catalysis, Max-Planck-Institut für Kohlenforschung, Kaiser-Wilhelm-Platz 1, 45470 Mülheim an der Ruhr, Germany \\ ${ }^{3}$ Helmholtz-Institute Erlangen-Nürnberg for Renewable Energy (IEK-11), Forschungszentrum Jülich, 91058 Erlangen, Germany \\ ${ }^{4}$ Department of Chemical and Biological Engineering, Friedrich-Alexander-Universität Erlangen-Nürnberg, 91058 Erlangen, Germany \\ ${ }^{5}$ Institute of Chemistry, Universidade Federal de Mato Grosso do Sul; Av. Senador Filinto Muller, 1555; Campo Grande, MS 79074-460, Brazil

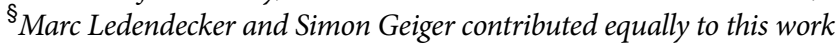

(c) The author(s) 2019.

Received: 21 December 2018 / Revised: 12 March 2019 / Accepted: 13 March 2019

\begin{abstract}
The reduction in noble metal content for efficient oxygen evolution catalysis is a crucial aspect towards the large scale commercialisation of polymer electrolyte membrane electrolyzers. Since catalytic stability and activity are inversely related, long service lifetime still demands large amounts of low-abundant and expensive iridium. In this manuscript we elaborate on the concept of maximizing the utilisation of iridium for the oxygen evolution reaction. By combining different tin oxide based support materials with liquid atomic layer deposition of iridium oxide, new possibilities are opened up to grow thin layers of iridium oxide with tuneable noble metal amounts. In-situ, time- and potential-resolved dissolution experiments reveal how the stability of the substrate and the catalyst layer thickness directly affect the activity and stability of deposited iridium oxide. Based on our results, we elaborate on strategies how to obtain stable and active catalysts with maximized iridium utilisation for the oxygen evolution reaction and demonstrate how the activity and durability can be tailored correspondingly. Our results highlight the potential of utilizing thin noble metal films with earth abundant support materials for future catalytic applications in the energy sector.
\end{abstract}

\section{KEYWORDS}

oxygen evolution reaction, liquid atomic layer deposition, catalysis, iridium, core-shell nanoparticles

\section{Introduction}

Ruthenium oxide $\left(\mathrm{RuO}_{x}\right)$ and iridium oxide $\left(\mathrm{IrO}_{x}\right)$ are the most promising catalyst materials for the acidic oxygen evolution reaction (OER), since they combine high intrinsic OER activities with high stability. While $\mathrm{RuO}_{x}$ is more active, it dissolves to a great extend during OER [1]. $\mathrm{IrO}_{x}$ in contrast, is typically more stable with slightly higher overpotentials, making it the material of choice in current electrolyzers [2-4]. Different types of Ir-based catalysts exist, ranging from homogeneous molecular catalysts to heterogeneous nanoparticulate, film or bulk catalysts. Heterogeneous iridium catalysts comprise different types of amorphous, hydrous oxide materials to crystalline oxides, perovskites $[5,6]$, pyrochlores $[7,8]$ or hollandites [9]. Of all named materials, crystalline $\operatorname{IrO}_{2 \text {-rutile }}$ demonstrates the highest stability and the lowest iridium-dissolution rates due to the formation of a dense, crystalline film, with low electrolyte accessibility to sub-surface iridium oxide and corner shared, so-called "activated oxygen atoms" [3]. The compact catalyst layer results in low overall mass activity since only the outer surface at the solid-liquid interface takes part in the reaction-The measured mass activity is therefore highly dependent on the particle dimensions.

Despite the excellent OER performance of iridium (oxides), their low abundancy, the often-arduous mining conditions and high price remain the major drawbacks for large scale applications of polymer electrolyte membrane electrolysers. A general trend in electrochemical energy conversion and in the whole field of catalytic applications is the reduction or even the full replacement of noble metals with abundant materials [10-12]. Given the fact that only the outer surface is participating in the catalytic reactions, the bulk could be replaced by less expensive materials-For nanoparticles the principle is known as core-shell concept. The main advantages can be summarized in three points: (i) The noble metal content can be substantially decreased since nearly all active atoms are at the surface and take place in the catalytic reaction; (ii) the underlying substrate could potentially affect the specific activity of the active material positively [13-16]; (iii) a stronger adhesion energy between core and shell material can increase the stability of the active surface elements [17-19]. Exemplarily, for spherical catalyst particles, the electrochemically active surface area (ECSA in $\mathrm{m}^{2} \cdot \mathrm{g}^{-1}$ ) and its dependency on core diameters and shell thicknesses is displayed in Fig. 1. When the noble metal shell is sufficiently thin, the active surface area drops only marginally despite the overall increase in particle size. When keeping the core diameter constant and increasing the shell thickness, however, the ECSA drops drastically, cancelling out the advantage of reduced shell dimensions.

A thin film of $\mathrm{IrO}_{2 \text {-rutile }}$ in the monolayer range on a cost-efficient support material would secure a high overall mass activity due to 


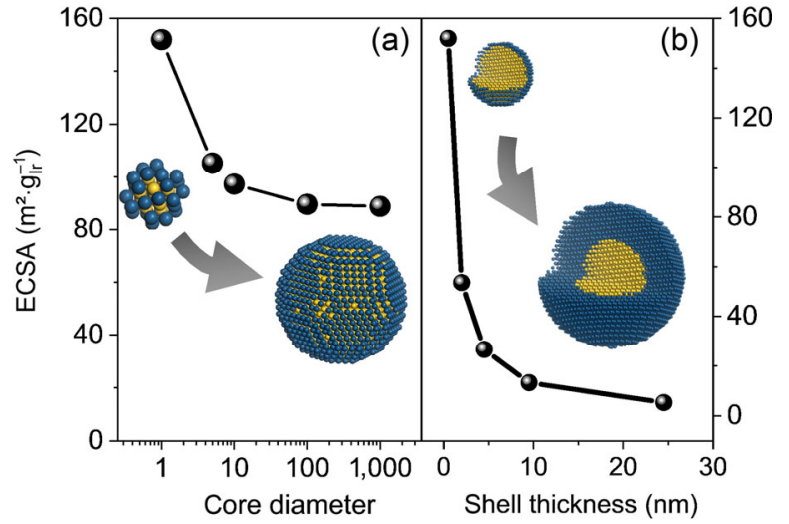

Figure 1 Maximizing the utilisation of noble metals in nanoparticles. Dependency of ECSA on (a) varying core diameters with a constant Ir-shell thickness $(0.5 \mathrm{~nm})$ and (b) varying shell thicknesses with constant core diameter $(1 \mathrm{~nm})$. The calculations result from geometric considerations-The details can be found in the ESM.

the high fraction of surface sites that can be utilized. Additionally, certain support materials, such as fluorine doped tin oxide (FTO) [20], antimony doped tin oxide (ATO) [21-23], indium tin oxide (ITO) [24], or $\mathrm{Nb}$-doped $\mathrm{TiO}_{2}[13,25-27]$ were reported to positively influence activity and stability of iridium-based catalysts.

In this manuscript, we concentrate on conductive tin oxide support materials and highlight the prerequisites, challenges and limits for OER catalysts with low iridium loading regarding stability and activity. Tin was used as support material due to its relative ease to obtain the necessary conductivity, its reported positive influence on the catalytic activity/stability and its over $10^{4}$ higher global primary production compared to iridium (data from 2010) [28]. We show that the further developed liquid atomic layer deposition (l-ALD) approach results in low amounts of iridium oxide that can be adapted depending on the amount of cycles applied. The feasibility of the proposed synthesis is shown exemplarily on model thin films allowing for facilitated in- and ex-situ characterisation. We demonstrate that the impact of substrate material, the degree of oxide formation, and the amount of catalyst is crucial for the described design principle which opens up new perspectives for the successful preparation of high-performance catalysts with maximized utilisation of precious iridium.

\section{Results and discussion}

\subsection{Self-adhered iridium complexes}

Anchored metal-complexes bridge the gap between heterogeneous and homogeneous catalysis with potential tunability of active sites. The concept seems appealing since the catalyst may be tailored to a specific reaction depending on the used ligands, while still maintaining its molecular identity during catalysis [29-35]. Therefore, we set out with molecular iridium complexes chemisorbed on oxide surfaces ( $\left.\mathrm{Ir}_{\text {complex }}\right)$ and tested their performance during OER as an all-surface catalyst $[30,32,36]$. The molecular structure of the used complex can be found in Fig. 2. By exchanging a bound water ligand with surface oxygen functionalities, the $\operatorname{Ir}_{\text {complex }}$ self-adheres to the surface of metal oxides at room temperature. Applying the same synthesis conditions, a (sub)monolayer of the $\operatorname{Ir}_{\text {complex }}$ was attached to an FTO and ITO coated glass slide (Fig. 2(a)). A detailed X-ray photoelectron spectroscopy analysis of the adhered complex can be found in the Electronic Supplementary Material (ESM). The as prepared catalyst was tested towards the OER in $0.1 \mathrm{M} \mathrm{HClO}_{4}$ as shown in Fig. S1(a) in the ESM. Normalized to geometric surface area, the first scan revealed rather low activity in comparison to pristine $\mathrm{IrO}_{2 \text {-rutile. }}$ However, activation via consecutive potential cycling significantly increased the activity, which originated from the formation of an amorphous $\mathrm{IrO}_{x}$ layer and the loss of organic ligands from the surface, as it was observed before for other electrocatalysts at high potentials $[37,38]$. This is in line with cyclic voltammetry curves displayed in Fig. S3 in the ESM which show the characteristic amorphous $\mathrm{IrO}_{x}$ pattern [39]. As stability metric for the OER, the stability number (S-number) was used in order to compare the stability to other OER-catalysts [3]. The S-number describes the number of dissolved metal atoms per one oxygen molecule formed and is independent of surface area, catalyst loading, and the number of active sites. The S-number of $\operatorname{Ir}_{\text {complex }}$ on FTO is relatively low and only $\sim 150$ oxygen atoms are produced per one iridium atom dissolved into the electrolyte (Fig. S1 in the ESM). Note that commonly used iridium-based materials possess S-numbers in the range of $10^{4}$ to $10^{6}$ (c.f. Fig. 4) [3].

\subsection{Liquid atomic layer deposition}

Since the heterogeneously attached iridium-complex fulfilled the prerequisites towards a maximized utilisation of iridium, but did not provide the necessary stability for long-term application, we extended the existing idea to a liquid atomic layer deposition approach [40]. One l-ALD cycle consists of the before described complex adsorption onto oxide surfaces (ITO, FTO) followed by thermal treatment in air. Reiteration of the self-limiting process leads to an adjustment of the iridium oxide loading which depends on the number of cycles. Due to the encountered difficulties in stability of the chemisorbed iridium complex, thermal oxidation of iridium was applied to aim at the formation of stable $\mathrm{IrO}_{2 \text {-rutile. Previous }}$ studies of iridium oxide on Ti substrates showed the highest OER (a)

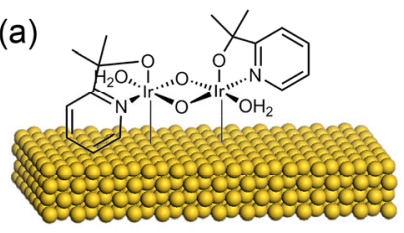

(b)
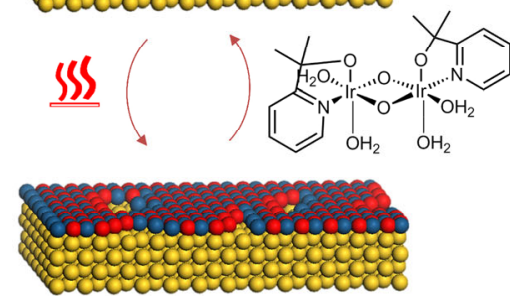

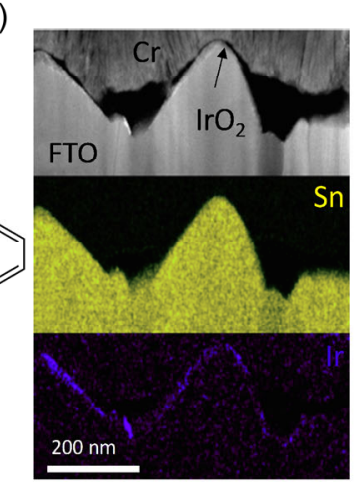

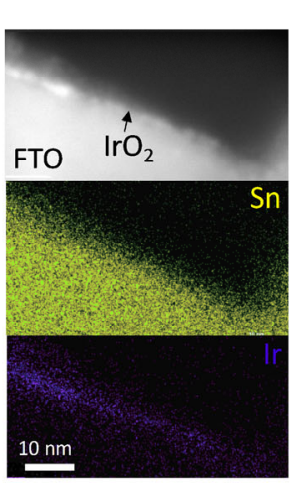

(c)

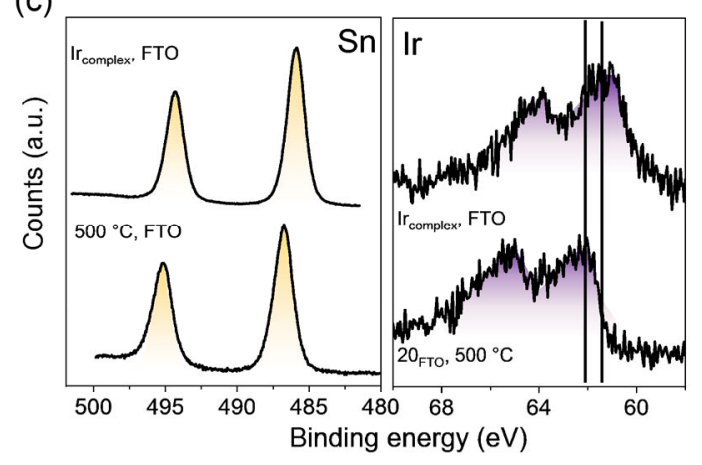

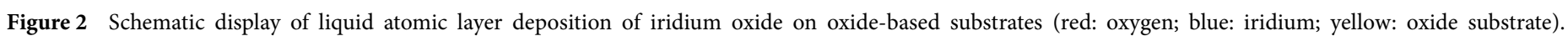

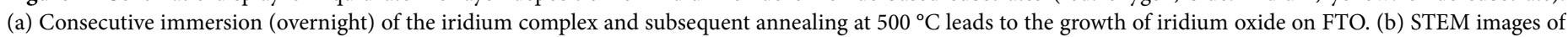

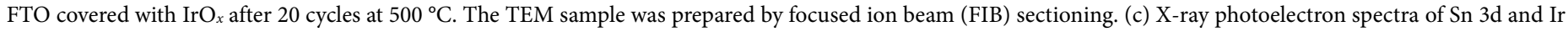
$4 \mathrm{f}$ levels of the complex adsorbed on the oxide surface (FTO) and after annealing at $500{ }^{\circ} \mathrm{C}$. A detailed analysis can be found in the ESM. 
activity after heat treatment between 250 and $350{ }^{\circ} \mathrm{C}$ [41]. The low temperatures, however, result in a high level of edge and defects sites with low overall dissolution stability $[3,42]$. The formation and

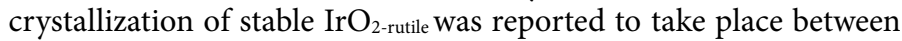
400 and $500{ }^{\circ} \mathrm{C}$, depending on the used precursors or substrates, which decreases the Ir-dissolution drastically [43, 44]. Therefore, each applied layer was treated for $30 \mathrm{~min}$ in air at $500{ }^{\circ} \mathrm{C}$ to form oxidized iridium species. For selected samples, the temperature of the last annealing step was increased to $600{ }^{\circ} \mathrm{C}$ for $5 \mathrm{~h}$ to maximize the transformation from (hydrous) $\operatorname{IrO}_{x}$ to $\operatorname{IrO}_{2 \text {-rutile }}[41,43,45]$. Note

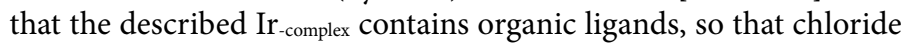
contamination reported for $\mathrm{IrCl}_{x}$ precursors could be excluded [44, 46]. Similar to classical ALD, several cycles are necessary to form one catalytic layer. Here, up to 20 cycles were applied. The iridium loading after one cycle was determined by inductively coupled plasma mass spectrometry (ICP-MS) to be $\sim 30 \mathrm{ng}_{\mathrm{Ir}} \cdot \mathrm{cm}^{-2}$.

In order to inspect the location of Ir with respect to $\mathrm{Sn}$, a lamella of $\mathrm{IrO}_{x}$ on FTO (20 cycles) was prepared by means of focused ion beam-scanning electron microscopy (FIB-SEM, FEI Helios NanoLab 600 , Fig. S2 in the ESM). The respective scanning transmission electron microscopy (STEM) images and elemental distribution maps are displayed in Fig. 2(b) demonstrating the general feasibility of the synthesis. Depending on the selected temperature, the formation of iridium-rich areas and the formation of an inhomogeneous film is observed (c.f. stability discussion). Especially $600{ }^{\circ} \mathrm{C}$ favors the reorganization of $\mathrm{IrO}_{x}$ as shown in Fig. S6 in the ESM. The increase in temperature results in higher Ir/Sn mobility and mixed oxide formation that goes along with surface restructuring and poor homogeneity. Narrow scans of the Ir $4 \mathrm{f}$ and $\mathrm{Sn} 3 \mathrm{~d}$ core levels determined by X-ray photoelectron spectroscopy of the $\operatorname{Ir}_{\text {complex }}$ chemisorbed on the FTO surface before and after thermal treatment $\left(500{ }^{\circ} \mathrm{C}\right)$ are shown in Fig. 2 . The shift of the $\mathrm{Ir} 4 \mathrm{f}_{7 / 2}$ peak from $61.4 \mathrm{eV}$ to $62.1 \mathrm{eV}$ reveals the increased formation of $\mathrm{IrO}_{2}[47,48]$. Simultaneously, a shift of the $3 \mathrm{~d}_{5 / 2}$ Sn core levels from 485.8 to $486.7 \mathrm{eV}$ indicates the formation of higher (mixed) oxides. The reason lies in the incorporation of $\operatorname{Ir}(\mathrm{IV})$ species into the tin oxide host lattice at these temperatures. The surface energies of $\mathrm{IrO}_{2 \text {-rutile }}$ are relatively higher compared to $\mathrm{SnO}_{2}$, making a thermodynamically driven growth of atomically smooth and fully formed layers challenging [49-51]. This is true for many oxides commonly used as support materials (e.g. $\mathrm{Nb}_{2} \mathrm{O}_{5}, \mathrm{TiO}_{2}, \mathrm{Ta}_{2} \mathrm{O}_{3}, \mathrm{Ta}_{2} \mathrm{O}_{5}$ ) when combined with $\mathrm{IrO}_{2}$. For Sn-based materials, the similar lattice parameters, the same valency of $\operatorname{Ir}(\mathrm{IV})$ and $\mathrm{Sn}(\mathrm{IV})$, similar radii, comparable electronegativities, and interfacial energies between $\mathrm{IrO}_{2}$-rutile and $\mathrm{SnO}_{2}$ favour the formation of mixed oxides [49-52]. In the following paragraphs, we will discuss the accompanying consequences of this dependency for (1) the activities and (2) the durability of the prepared catalysts.

\subsection{Electrocatalytic activity towards the OER}

The polarisation curves after different adsorption cycles of $\operatorname{Ir}_{\text {complex }}$ on FTO and ITO substrates at different temperatures are displayed in Fig. 3(a). The study of various samples of $\operatorname{IrO}_{x}$ on FTO $(1,5,15$, and 20 cycles) reveals that the OER activity scales with the amount of iridium deposited. $\mathrm{IrO}_{x}$ on FTO obtained by 20 consecutive cycles results in high utilization of a stable iridium oxide structure, close to the ideal and theoretical value of mass normalized activity

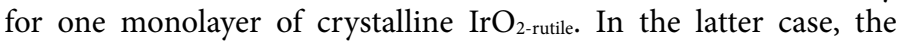
participation of one monolayer was assumed corresponding to $150 \mathrm{ng}_{\mathrm{Ir}} \cdot \mathrm{cm}^{-2}$ for the 001 facet of $\mathrm{IrO}_{2 \text {-rutile. }}$.

ITO was used as support material for comparison. Here, the same amount of cycles (here 5 cycles) result in much higher OER activities which can be explained by several consecutive effects. As stated before, iridium, tin, and indium oxides are susceptible to the formation of mixed oxides at high temperatures (e.g. $\operatorname{Ir}_{1-x} \mathrm{Sn}_{x} \mathrm{O}_{2}$ and $\operatorname{Ir}_{1-x} \operatorname{In}_{x} \mathrm{O}_{y}$ mixed phases) $[1,39]$. For ITO, In and Sn dissolve significantly when brought in contact with low $\mathrm{pH}$ solutions. The leached In and $\mathrm{Sn}$ from the formed $\operatorname{Ir}_{1-x} \mathrm{Sn}_{x} \mathrm{O}_{2}$ and $\operatorname{Ir}_{1-x} \operatorname{In}_{x} \mathrm{O}_{y}$ mixed phases increase the overall surface roughness and result in an "amorphous-like" $\mathrm{IrO}_{x}$ layer with a low amount of interconnected Ir-O-Ir networks and enhanced edge effects. A similar effect was observed for IrNi-based materials when the non-noble metal leaches during catalysis. The created lattice vacancies generate an unusually large number of $d$-band holes in the iridium oxide material which results in the observed low kinetic barrier during catalysis [53]. Similarly, the presence of vacancies and defects in cobalt/iron based layered double hydroxides was found to result in higher OER activity in alkaline medium [54]. The role of defects on the OER performance is discussed in detail in Ref. [55]. This observation is also expressed by the varying Tafel slopes obtained for $\mathrm{IrO}_{x}$ on FTO and ITO as discussed in detail in the ESM. While overall this leads to an initial activation of ITO-based samples, long-term performance most likely suffers from the amorphization induced by the leaching process. Figure 3 compares the activity of various catalysts when normalized to the charge associated to the transition from Ir(III) to (a)

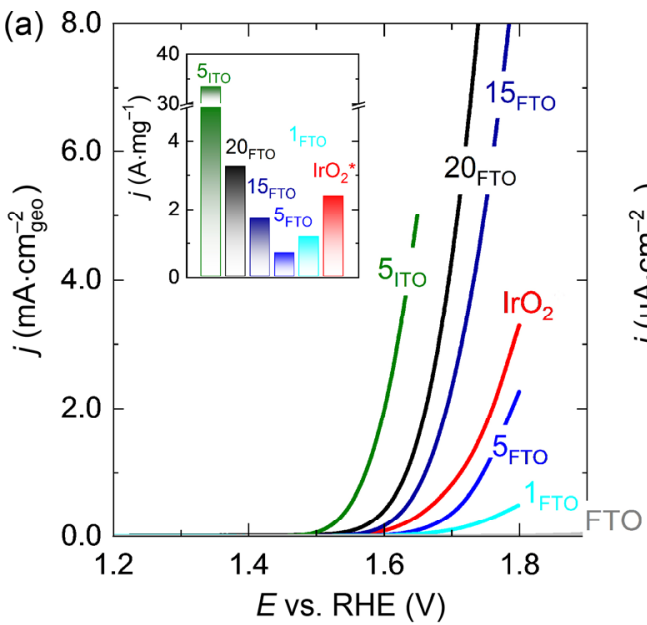

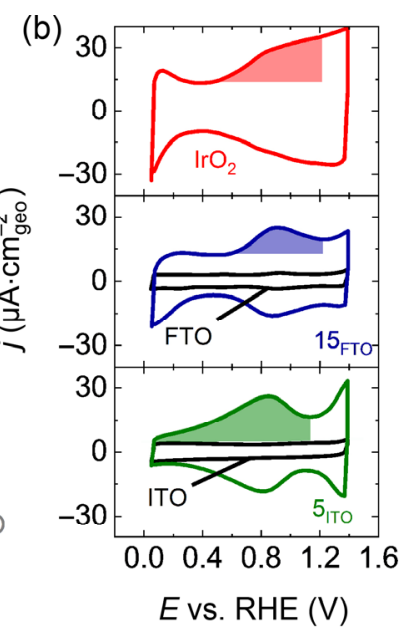

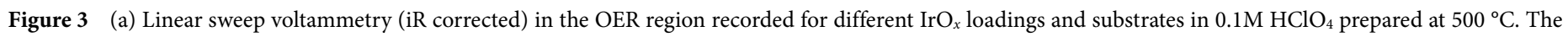

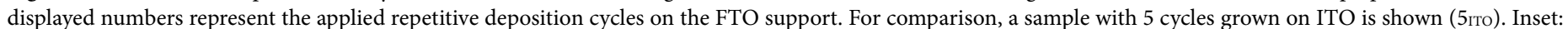

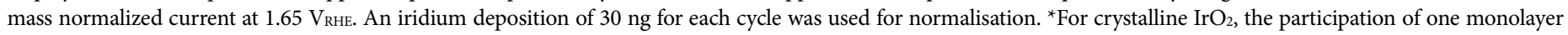

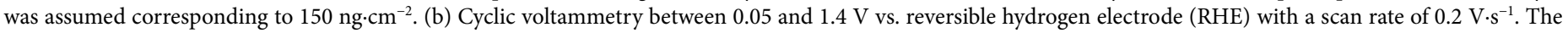

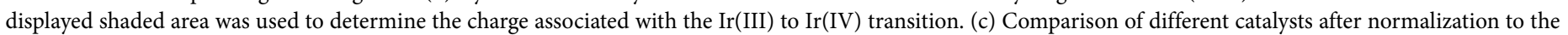
obtained charge from cyclic voltammetry indicated in (b). $\mathrm{Ba}_{2} \mathrm{PrIrO}_{6}$ was added as reference catalysts with one of the highest activities reported in Refs. $[3,5,6]$. 
$\operatorname{Ir}(\mathrm{IV})$ (as shown in Fig. 3). The ITO-based catalyst is as active as $\mathrm{Ba}_{2} \mathrm{PrIrO}_{6}$, a perovskite material with one of the highest reported activities $[3,5,6] . \mathrm{IrO}_{x}$ on FTO possesses a lower specific activity compared to $\mathrm{IrO}_{x}$ on ITO. The activity is still higher compared to pristine $\mathrm{IrO}_{2}$, presumably caused by the lower calcination temperature of $500{ }^{\circ} \mathrm{C}$. When annealed to $600^{\circ} \mathrm{C}$, the specific activities of $\operatorname{IrO}_{x}$ on FTO resemble the specific activity of crystalline $\mathrm{IrO}_{2 \text {-rutile }}$ (Fig. S4 in the ESM). The determination of the electrochemically active surface area and specific activity, however, still remains challenging for iridium-based materials. In contrast, iridium mass-normalized activities enable a practical comparison between various catalysts as shown in Fig. 1, inset. The loaded iridium content was determined through inductively coupled plasma mass spectrometry (ICP-MS) measurements and compared with the active charge capacity of the $\mathrm{Ir}^{\mathrm{III}} / \mathrm{Ir}^{\mathrm{IV}}$ transition (c.f. ESM). The hydrous iridium oxide formed on ITO results in a high mass-based activity of $\sim 35 \mathrm{~A} \cdot \mathrm{mg}_{\mathrm{Ir}}{ }^{-1}$ at $1.65 \mathrm{~V}$ vs. RHE ( 5 cycles). This "all surface catalyst" contains low amounts of deposited material, overall high accessibility to active sites and belongs to the most active catalyst reported in Ref. [6]. For FTO, the highest mass activity was observed for 20 repetitive cycles, resulting in a mass-based activity of $\sim 2.5 \mathrm{~A} \cdot \mathrm{mg}_{\mathrm{Ir}}{ }^{-1}$ at $1.65 \mathrm{~V}$ vs. RHE. The specific and mass activities are therefore highly susceptible to the support material employed. In order to shed more light on the ongoing processes during electrocatalysis, in-situ dissolution studies were performed.

\subsection{Electrocatalytic stability}

The observed activity was correlated with its intrinsic stability and galvanostatic polarisation at $1 \mathrm{~mA} \cdot \mathrm{cm}^{-2}$ of all materials was performed. Over the used time interval, the respective elemental dissolution was measured by means of a flow cell (FC) coupled on-line to an ICP-MS until quasi steady state conditions were reached (Fig. 4(a)). A detailed description of the used technique can be found in the ESM and in Refs. [43, 56]. The S-number for each material is estimated from the integrated amount of dissolved metal under quasi steady state conditions and the amount of produced oxygen assuming $100 \%$ faradaic efficiency (see Fig. 4(b)). The utilization of different substrates results in very different stability behaviour. Highly active $\mathrm{IrO}_{x}$ on ITO dissolves to a high extent, while $\mathrm{IrO}_{x}$ on FTO is significantly more stable, caused by the different extent of amorphous (on ITO) and crystalline character (on FTO) of the respective $\mathrm{IrO}_{x}$ phases (c.f. amorphous $\mathrm{IrO}_{x}$ as reference catalyst, Fig. 4(b)). While the choice of stable support material leads to overall higher stability of the catalyst/support system, the temperature influence on the formation of mixed oxides poses substantial challenges to the use of $\mathrm{IrO}_{2} / \mathrm{SnO}_{2}$-based materials. Indirect corroboration of the previously described mixed oxide formation was found when the dissolution and electrochemical behaviour of pristine FTO was compared to FTO where 15 consecutive cycles of $\mathrm{IrO}_{x}$ deposition were applied (Fig. S7 in the ESM). For pristine FTO, no dissolution of $\mathrm{Sn}$ was observed even up to $2 \mathrm{~V}_{\mathrm{RHE}}$ while Sn dissolution was observed for $15_{\text {FTO }}$ that matches the dissolution profile of Ir.

Additional annealing at $600{ }^{\circ} \mathrm{C}$ for $5 \mathrm{~h}$ increases the stability of

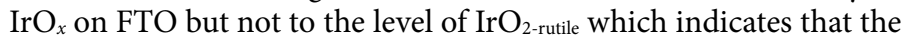
formation of $\operatorname{Ir}_{1-x} \mathrm{Sn}_{x} \mathrm{O}_{2}$ mixed oxides has negative effects on the stability of the whole catalytic system. Additionally, annealing at $600{ }^{\circ} \mathrm{C}$ has negative consequences for both, the specific and the mass activity (Fig. S4 in the ESM). The predicament lies therefore in the formation of a dense, crystalline $\mathrm{IrO}_{2}$-rutile film with a high amount of interconnected Ir-O-Ir units during thermal annealing, conditions that, however, also favor increased mobility of surface atoms and the formation of less stable mixed oxides compared to

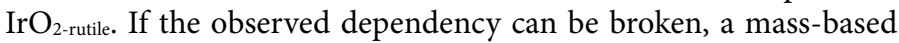
activity close to the most active iridium-based materials can be obtained while keeping the stability in the range of $\mathrm{IrO}_{2 \text {-rutile. }}$ Our results suggest that an active and stable "all surface" $\mathrm{IrO}_{2 \text {-rutile }}$ catalyst on an (oxide) support material has to fulfill the prerequisites of low intermixing and a high number of Ir-O-Ir networks that anchors Ir in place while keeping the total $\mathrm{IrO}_{2 \text {-rutile }}$ thickness in the monolayer regime.

\section{Conclusion}

We have shown that post-grafted Ir-organo-complexes are not stable in the harsh environment that the acidic oxygen evolution reaction demands. A further developed synthesis method is proposed that consists of a liquid atomic layer deposition approach. Here, an Ir-organo-complex is attached to an oxide surface and subsequently oxidized. Depending on the amount of repetitive cycles, different catalyst loadings can be obtained. We demonstrate that the stability of the support material has drastic consequences for the activity and stability of the catalyst material. While one of the highest reported specific and mass-based activities were obtained on ITO, the utilization of stabilized surface $\mathrm{IrO}_{2 \text {-rutile }}$ is at its maximum for FTO as substrate. The higher surface energy of $\mathrm{IrO}_{2 \text {-rutile }}$ compared to $\mathrm{SnO}_{2 \text {-rutile }}$ and the driving force for intermixing at high temperatures poses substantial challenges to the synthesis of stable and active OER catalysts based on the combination of iridium- and tin oxide based materials. By breaking the dependency of forming of a dense, crystalline $\mathrm{IrO}_{2 \text {-rutile }}$ film with a high amount of interconnected Ir-O-Ir units and increased mobility of surface atoms at high temperatures, it is suggested that a mass specific activity close to the most active iridium oxide-based materials can
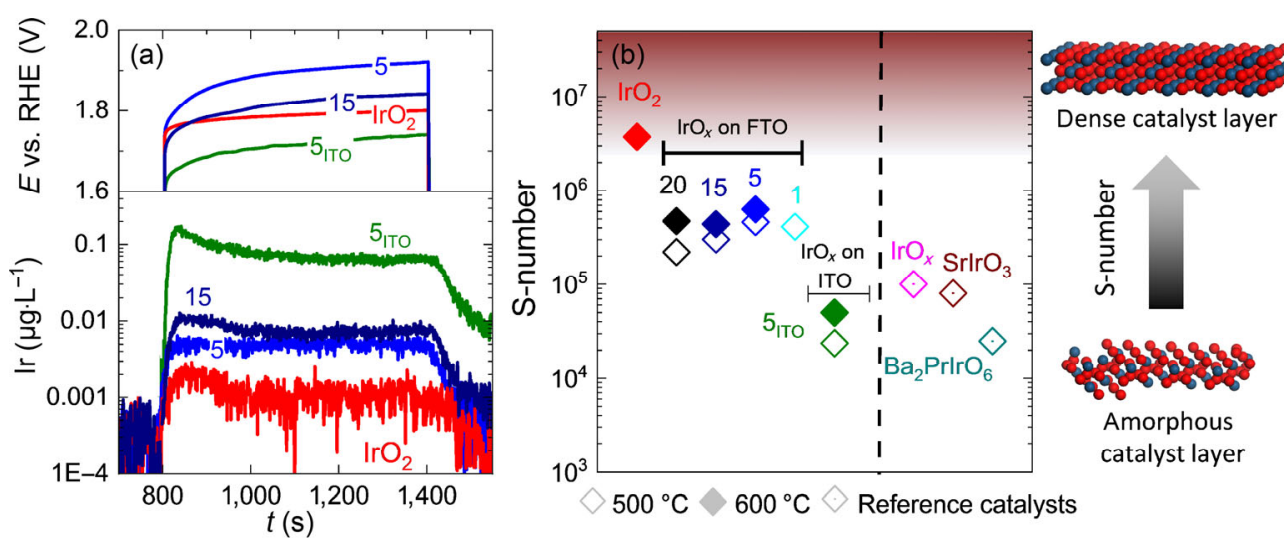

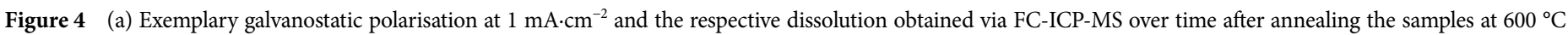

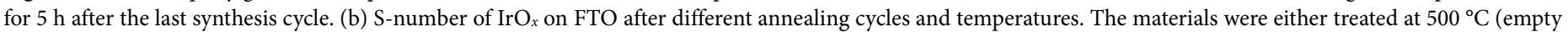
squares) or at $600^{\circ} \mathrm{C}$ for $5 \mathrm{~h}$ (full squares). Reference state-of-the-art materials were added for comparison [3]. All measurements were carried out in $0.1 \mathrm{HClO} 4$. 
be obtained, while keeping the dissolution stability high and reducing the overall costs.

\section{Acknowledgements}

This research has been funded by the Federal Ministry for Economic Affairs and Energy (BMWi) of Germany in the framework of PtTM@HGS (No. 03ET6080A). G. V. F. thanks CAPES for the PDSE fellowship (No. 88881.131904/2016-01).

\section{Funding}

Open access funding provided by Max Planck Society.

Electronic Supplementary Material: Supplementary material (further details on the synthesis procedures, characterization and additional catalytic tests) is available in the online version of this article at https://doi.org/10.1007/s12274-019-2383-y.

Open Access: This article is licensed under a Creative Commons Attribution 4.0 International License, which permits use, sharing, adaptation, distribution and reproduction in any medium or format as long as you give appropriate credit to the original author(s) and the source, provide a link to the Creative Commons licence, and indicate if changes were made.

The images or other third party material in this article are included in the article's Creative Commons licence, unless indicated otherwise in a credit line to the material. If material is not included in the article's Creative Commons licence and your intended use is not permitted by statutory regulation or exceeds the permitted use, you will need to obtain permission directly from the copyright holder.

To view a copy of this licence, visit http://creativecommons.org/ licenses/by/4.0/.

\section{References}

[1] Kasian, O.; Geiger, S.; Stock, P.; Polymeros, G.; Breitbach, B.; Savan, A.; Ludwig, A.; Cherevko, S.; Mayrhofer, K. J. J. On the origin of the improved ruthenium stability in $\mathrm{RuO}_{2}-\mathrm{IrO}_{2}$ mixed oxides. J. Electrochem. Soc. 2016, 163, F3099-F3104.

[2] Cherevko, S.; Zeradjanin, A. R.; Topalov, A. A.; Kulyk, N.; Katsounaros, I.; Mayrhofer, K. J. J. Dissolution of noble metals during oxygen evolution in acidic media. ChemCatChem 2014, 6, 2219-2223.

[3] Geiger, S.; Kasian, O.; Ledendecker, M.; Pizzutilo, E.; Mingers, A. M.; Fu, W. T.; Diaz-Morales, O.; Li, Z. Z.; Oellers, T.; Fruchter, L. et al. The stability number as a metric for electrocatalyst stability benchmarking. Nat. Catal. 2018, 1, 508-515.

[4] Cherevko, S.; Geiger, S.; Kasian, O.; Kulyk, N.; Grote, J. P.; Savan, A.; Shrestha, B. R.; Merzlikin, S.; Breitbach, B.; Ludwig, A. et al. Oxygen and hydrogen evolution reactions on $\mathrm{Ru}, \mathrm{RuO}_{2}, \mathrm{Ir}$, and $\mathrm{IrO}_{2}$ thin film electrodes in acidic and alkaline electrolytes: A comparative study on activity and stability. Catal. Today 2016, 262, 170-180.

[5] Seitz, L. C.; Dickens, C. F.; Nishio, K.; Hikita, Y.; Montoya, J.; Doyle, A.; Kirk, C.; Vojvodic, A.; Hwang, H. Y.; Norskov, J. K. et al. A highly active and stable $\mathrm{IrO}_{x} / \mathrm{SrIrO}_{3}$ catalyst for the oxygen evolution reaction. Science 2016, 353, 1011-1014.

[6] Diaz-Morales, O.; Raaijman, S.; Kortlever, R.; Kooyman, P. J.; Wezendonk, T.; Gascon, J.; Fu, W. T.; Koper, M. T. M. Iridium-based double perovskites for efficient water oxidation in acid media. Nat. Commun. 2016, 7, 12363.

[7] Sardar, K.; Petrucco, E.; Hiley, C. I.; Sharman, J. D. B.; Wells, P. P.; Russell, A. E.; Kashtiban, R. J.; Sloan, J.; Walton, R. I. Water-splitting electrocatalysis in acid conditions using ruthenate-iridate pyrochlores. Angew. Chem., Int. Ed. 2014, 53, 10960-10964.

[8] Sun, W.; Liu, J. Y.; Gong, X. Q.; Zaman, W. Q.; Cao, L. M.; Yang, J. OER activity manipulated by $\mathrm{IrO}_{6}$ coordination geometry: An insight from pyrochlore iridates. Sci. Rep. 2016, 6, 38429.

[9] Sun, W.; Song, Y.; Gong, X. Q.; Cao, L. M.; Yang, J. Hollandite structure
$\mathrm{K}_{x \approx 0.25} \mathrm{IrO}_{2}$ catalyst with Highly efficient oxygen evolution reaction. $A C S$ Appl. Mater. Interfaces 2016, 8, 820-826.

[10] Ledendecker, M.; Krick Calderón, S.; Papp, C.; Steinrück, H. P.; Antonietti, M.; Shalom, M. The synthesis of nanostructured $\mathrm{Ni}_{5} \mathrm{P}_{4}$ films and their use as a non-noble bifunctional electrocatalyst for full water splitting. Angew. Chem., Int. Ed. 2015, 54, 12361-12365.

[11] Ledendecker, M.; Mondschein, J. S.; Kasian, O.; Geiger, S.; Göhl, D.; Schalenbach, M.; Zeradjanin, A.; Cherevko, S.; Schaak, R. E.; Mayrhofer, K. Stability and activity of non-noble-metal-based catalysts toward the hydrogen evolution reaction. Angew. Chem., Int. Ed. 2017, 56, 97679771.

[12] Schalenbach, M.; Speck, F. D.; Ledendecker, M.; Kasian, O.; Goehl, D.; Mingers, A. M.; Breitbach, B.; Springer, H.; Cherevko, S.; Mayrhofer, K. J. J. Nickel-molybdenum alloy catalysts for the hydrogen evolution reaction: Activity and stability revised. Electrochim. Acta 2018, 259, $1154-1161$.

[13] Oh, H. S.; Nong, H. N.; Reier, T.; Bergmann, A.; Gliech, M.; de Araújo, J. F.; Willinger, E.; Schlögl, R.; Teschner, D.; Strasser, P. Electrochemical catalyst-support effects and their stabilizing role for $\mathrm{IrO}_{x}$ nanoparticle catalysts during the oxygen evolution reaction. J. Am. Chem. Soc. 2016, $138,12552-12563$.

[14] Strasser, P.; Koh, S.; Anniyev, T.; Greeley, J.; More, K.; Yu, C. F.; Liu, Z. C.; Kaya, S.; Nordlund, D.; Ogasawara, H. et al. Lattice-strain control of the activity in dealloyed core-shell fuel cell catalysts. Nat. Chem. 2010, 2, $454-460$.

[15] Stamenkovic, V. R.; Mun, B. S.; Arenz, M.; Mayrhofer, K. J. J.; Lucas, C. A.; Wang, G. F.; Ross, P. N.; Markovic, N. M. Trends in electrocatalysis on extended and nanoscale Pt-bimetallic alloy surfaces. Nat. Mater. 2007, $6,241-247$.

[16] Stamenkovic, V.; Mun, B. S.; Mayrhofer, K. J. J.; Ross, P. N.; Markovic, N. M.; Rossmeisl, J.; Greeley, J.; Nørskov, J. K. Changing the activity of electrocatalysts for oxygen reduction by tuning the surface electronic structure. Angew. Chem. 2006, 118, 2963-2967.

[17] Hsieh, Y. C.; Zhang, Y.; Su, D.; Volkov, V.; Si, R.; Wu, L. J.; Zhu, Y. M.; An, W.; Liu, P.; He, P. et al. Ordered bilayer ruthenium-platinum core-shell nanoparticles as carbon monoxide-tolerant fuel cell catalysts. Nat. Commun. 2013, 4, 2466.

[18] Wang, L.; Gao, W. P.; Liu, Z. Y.; Zeng, Z. H.; Liu, Y. F.; Giroux, M.; Chi, M. F.; Wang, G. F.; Greeley, J.; Pan, X. Q. et al. Core-shell nanostructured cobalt-platinum electrocatalysts with enhanced durability. ACS Catal. 2018, $8,35-42$.

[19] Wang, J. X.; Inada, H.; Wu, L. J.; Zhu, Y. M.; Choi, Y.; Liu, P.; Zhou, W. P.; Adzic, R. R. Oxygen reduction on well-defined core-shell nanocatalysts: Particle size, Facet, and Pt shell thickness effects. J. Am. Chem. Soc. 2009, 131, 17298-17302.

[20] Geiger, S.; Kasian, O.; Mingers, A. M.; Mayrhofer, K. J. J.; Cherevko, S. Stability limits of tin-based electrocatalyst supports. Sci. Rep. 2017, 7, 4595.

[21] Nong, H. N.; Oh, H. S.; Reier, T.; Willinger, E.; Willinger, M. G.; Petkov, V.; Teschner, D.; Strasser, P. Oxide-supported $\mathrm{IrNiO}_{x}$ core-shell particles as efficient, cost-effective, and stable catalysts for electrochemical water splitting. Angew. Chem., Int. Ed. 2015, 54, 2975-2979.

[22] Oh, H. S.; Nong, H. N.; Reier, T.; Gliech, M.; Strasser, P. Oxide-supported Ir nanodendrites with high activity and durability for the oxygen evolution reaction in acid PEM water electrolyzers. Chem. Sci. 2015, 6, 3321-3328.

[23] Puthiyapura, V. K.; Mamlouk, M.; Pasupathi, S.; Pollet, B. G.; Scott, K. Physical and electrochemical evaluation of ATO supported $\mathrm{IrO}_{2}$ catalyst for proton exchange membrane water electrolyser. J. Power Sources 2014, $269,451-460$.

[24] Puthiyapura, V. K.; Pasupathi, S.; Su, H. N.; Liu, X. T.; Pollet, B.; Scott, K. Investigation of supported $\mathrm{IrO}_{2}$ as electrocatalyst for the oxygen evolution reaction in proton exchange membrane water electrolyser. Int. J. Hydrogen Energy 2014, 39, 1905-1913.

[25] Kadakia, K. S.; Jampani, P. H.; Velikokhatnyi, O. I.; Datta, M. K.; Park, S. K.; Hong, D. H.; Chung, S. J.; Kumta, P. N. Nanostructured F doped $\mathrm{IrO}_{2}$ electro-catalyst powders for PEM based water electrolysis. J. Power Sources 2014, 269, 855-865.

[26] Velikokhatnyi, O. I.; Kadakia, K.; Datta, M. K.; Kumta, P. N. Fluorine-doped $\mathrm{IrO}_{2}$ : A potential electrocatalyst for water electrolysis. $J$. Phys. Chem. C 2013, 117, 20542-20547.

[27] Kadakia, K.; Datta, M. K.; Velikokhatnyi, O. I.; Jampani, P.; Park, S. K.; Saha, P.; Poston, J. A.; Manivannan, A.; Kumta, P. N. Novel (Ir, Sn, Nb)O 
anode electrocatalysts with reduced noble metal content for PEM based water electrolysis. Int. J. Hydrogen Energy 2012, 37, 3001-3013.

[28] Vesborg, P. C. K.; Jaramillo, T. F. Addressing the terawatt challenge: Scalability in the supply of chemical elements for renewable energy. RSC Adv. 2012, 2, 7933-7947.

[29] García-Melchor, M.; Vilella, L.; López, N.; Vojvodic, A. Computationally probing the performance of hybrid, heterogeneous, and homogeneous iridium-based catalysts for water oxidation. ChemCatChem 2016, 8, 1792-1798.

[30] Schley, N. D.; Blakemore, J. D.; Subbaiyan, N. K.; Incarvito, C. D.; D’Souza, F.; Crabtree, R. H.; Brudvig, G. W. Distinguishing homogeneous from heterogeneous catalysis in electrode-driven water oxidation with molecular iridium complexes. J. Am. Chem. Soc. 2011, 133, 10473-10481.

[31] Sheehan, S. W.; Thomsen, J. M.; Hintermair, U.; Crabtree, R. H.; Brudvig, G. W.; Schmuttenmaer, C. A. A molecular catalyst for water oxidation that binds to metal oxide surfaces. Nat. Commun. 2015, 6, 6469.

[32] Thomsen, J. M.; Sheehan, S. W.; Hashmi, S. M.; Campos, J.; Hintermair, U.; Crabtree, R. H.; Brudvig, G. W. Electrochemical activation of Cp* iridium complexes for electrode-driven water-oxidation catalysis. $J$. Am. Chem. Soc. 2014, 136, 13826-13834.

[33] Hull, J. F.; Balcells, D.; Blakemore, J. D.; Incarvito, C. D.; Eisenstein, O.; Brudvig, G. W.; Crabtree, R. H. Highly active and robust $\mathrm{Cp}^{*}$ iridium complexes for catalytic water oxidation. J. Am. Chem. Soc. 2009, 131, 8730-8731.

[34] Hetterscheid, D. G. H.; Reek, J. N. H. $\mathrm{Me}_{2}-\mathrm{NHC}$ based robust Ir catalyst for efficient water oxidation. Chem. Commun. 2011, 47, 2712-2714.

[35] Hintermair, U.; Sheehan, S. W.; Parent, A. R.; Ess, D. H.; Richens, D. T.; Vaccaro, P. H.; Brudvig, G. W.; Crabtree, R. H. Precursor transformation during molecular oxidation catalysis with organometallic iridium complexes. J. Am. Chem. Soc. 2013, 135, 10837-10851.

[36] Sheehan, S. W.; Thomsen, J. M.; Hintermair, U.; Crabtree, R. H.; Brudvig, G. W.; Schmuttenmaer, C. A. A molecular catalyst for water oxidation that binds to metal oxide surfaces. Nat. Commun. 2015, 6, 6469.

[37] Saruyama, M.; Kim, S.; Nishino, T.; Sakamoto, M.; Haruta, M.; Kurata, H.; Akiyama, S.; Yamada, T.; Domen, K.; Teranishi, T. Phase-segregated $\mathrm{NiP}_{x} @ \mathrm{FeP}_{y} \mathrm{O}_{z}$ core@shell nanoparticles: Ready-to-use nanocatalysts for electro- and photo-catalytic water oxidation through in situ activation by structural transformation and spontaneous ligand removal. Chem. Sci. 2018, 9, 4830-4836.

[38] Pizzutilo, E.; Knossalla, J.; Geiger, S.; Grote, J. P.; Polymeros, G.; Baldizzone, C.; Mezzavilla, S.; Ledendecker, M.; Mingers, A.; Cherevko, $\mathrm{S}$. et al. The space confinement approach using hollow graphitic spheres to unveil activity and stability of Pt-Co nanocatalysts for PEMFC. $A d v$. Energy Mater. 2017, 7, 1700835.

[39] De Pauli, C. P.; Trasatti, S. Electrochemical surface characterization of $\mathrm{IrO}_{2}+\mathrm{SnO}_{2}$ mixed oxide electrocatalysts. J. Electroanal. Chem. 1995, 396, 161-168.

[40] Wu, Y. L.; Döhler, D.; Barr, M.; Oks, E.; Wolf, M.; Santinacci, L.; Bachmann, J. Atomic layer deposition from dissolved precursors. Nano Lett. 2015, 15, 6379-6385.

[41] Reier, T.; Teschner, D.; Lunkenbein, T.; Bergmann, A.; Selve, S.;
Kraehnert, R.; Schlögl, R.; Strasser, P. Electrocatalytic oxygen evolution on iridium oxide: Uncovering catalyst-substrate interactions and active iridium oxide species. J. Electrochem. Soc. 2014, 161, F876-F882.

[42] Gottesfeld, S.; Srinivasan, S. Electrochemical and optical studies of thick oxide layers on iridium and their electrocatalytic activities for the oxygen evolution reaction. J. Electroanal. Chem. Interfacial Electrochem. 1978, 86, 89-104.

[43] Geiger, S.; Kasian, O.; Shrestha, B. R.; Mingers, A. M.; Mayrhofer, K. J. J.; Cherevko, S. Activity and stability of electrochemically and thermally treated iridium for the oxygen evolution reaction. J. Electrochem. Soc. 2016, 163, F3132-F3138.

[44] Lodi, G.; De Battisti, A.; Benedetti, A.; Fagherazzi, G.; Kristof, J. Formation of iridium metal in thermally prepared iridium dioxide coatings. J. Electroanal. Chem. Interfacial Electrochem. 1988, 256, 441-445.

[45] Hu, W.; Chen, S. L. Grain size effect of $\mathrm{IrO}_{2}$ nanocatalysts for the oxygen evolution reaction. Wuhan Univ. J. Nat. Sci. 2013, 18, 289-294.

[46] Trasatti, S. Electrocatalysis in the anodic evolution of oxygen and chlorine. Electrochim. Acta 1984, 29, 1503-1512.

[47] Kötz, R.; Neff, H.; Stucki, S. Anodic iridium oxide films: XPS-studies of oxidation state changes and $O_{2}$ evolution. J. Electrochem. Soc. 1984, 131, $72-77$.

[48] Pfeifer, V.; Jones, T. E.; Velasco Vélez, J. J.; Massué, C.; Greiner, M. T.; Arrigo, R.; Teschner, D.; Girgsdies, F.; Scherzer, M.; Allan, J. et al. The electronic structure of iridium oxide electrodes active in water splitting. Phys. Chem. Chem. Phys. 2016, 18, 2292-2296.

[49] Kim, J. S.; Friend, R. H.; Cacialli, F. Surface energy and polarity of treated indium-tin-oxide anodes for polymer light-emitting diodes studied by contact-angle measurements. J. Appl. Phys. 1999, 86, 2774-2778.

[50] Matz, O.; Calatayud, M. Periodic DFT study of rutile $\mathrm{IrO}_{2}$ : Surface reactivity and catechol adsorption. J. Phys. Chem. C 2017, 121, 13135-13143.

[51] Sen, F. G.; Kinaci, A.; Narayanan, B.; Gray, S. K.; Davis, M. J.; Sankaranarayanan, S. K. R. S.; Chan, M. K. Y. Towards accurate prediction of catalytic activity in $\mathrm{IrO}_{2}$ nanoclusters via first principles-based variable charge force field. J. Mater. Chem. A 2015, 3, 18970-18982.

[52] Wang, X.; Yin, Q. Q.; Tang, Z. Z.; Liu, X. H.; Tang, D.; Lin, W. The nature of phase separation in Ir-Sn-O ternary oxide electrocatalyst. J. Eur. Ceram. Soc. 2013, 33, 3045-3052.

[53] Nong, H. N.; Reier, T.; Oh, H. S.; Gliech, M.; Paciok, P.; Vu, T. H. T.; Teschner, D.; Heggen, M.; Petkov, V.; Schlögl, R. et al. A unique oxygen ligand environment facilitates water oxidation in hole-doped $\mathrm{IrNiO}_{x}$ core-shell electrocatalysts. Nat. Catal. 2018, 1, 841-851.

[54] Wang, Y. Y.; Zhang, Y. Q.; Liu, Z. J.; Xie, C.; Feng, S.; Liu, D. D.; Shao, M. F.; Wang, S. Y. Layered double hydroxide nanosheets with multiple vacancies obtained by dry exfoliation as highly efficient oxygen evolution electrocatalysts. Angew. Chem., Int. Ed. 2017, 56, 5867-5871.

[55] Yan, D. F.; Li, Y. X.; Huo, J.; Chen, R.; Dai, L. M.; Wang, S. Y. Defect chemistry of nonprecious-metal electrocatalysts for oxygen reactions. $A d v$. Mater. 2017, 29, 1606459

[56] Klemm, S. O.; Topalov, A. A.; Laska, C. A.; Mayrhofer, K. J. J. Coupling of a high throughput microelectrochemical cell with online multielemental trace analysis by ICP-MS. Electrochem. Commun. 2011, 13, 1533-1535. 